\title{
Basic Concepts of the Modern Educational Process in Teaching Mathematics
}

\author{
Dragan Obradovic ${ }^{1}$, Lakshmi Narayan Mishra ${ }^{2,}$, Vishnu Narayan Mishra ${ }^{3}$ \\ ${ }^{1}$ Elementary School "Jovan Cvijic", Kostolac, Pozarevac, Serbia \\ ${ }^{2}$ Department of Mathematics, School of Advanced Sciences, Vellore Institute of Technology (VIT) University, Vellore, Tamil Nadu, India \\ ${ }^{3}$ Department of Mathematics, Indira Gandhi National Tribal University, Amarkantak, Anuppur, Madhya Pradesh, India
}

\section{Email address:}

dragishaobradovic@yahoo.com (D. Obradovic), lakshminarayanmishra04@gmail.com (L. N. Mishra),

vishnunarayanmishra@gmail.com (V. N. Mishra)

${ }^{*}$ Corresponding author

\section{To cite this article:}

Dragan Obradovic, Lakshmi Narayan Mishra, Vishnu Narayan Mishra. Basic Concepts of the Modern Educational Process in Teaching Mathematics. International Journal of Theoretical and Applied Mathematics. Vol. 6, No. 6, 2020, pp. 88-94.

doi: $10.11648 /$ j.ijtam.20200606.11

Received: November 8, 2020; Accepted: November 23, 2020; Published: December 11, 2020

\begin{abstract}
The paper analyzes the possibility of realization of the principle of individualization of mathematics teaching in the didactic system of teaching with the help of computers. In addition to the presentation of the function of computers in this teaching system and the student - computer - teacher relationship, some important characteristics of educational software in mathematics teaching are given. The presented analysis, based on the current level of development of information technologies, computers, educational software, the internet, their role and place in the teaching process, should show that computer-assisted teaching fully encompasses all static and dynamic parameters of individualization, ie. that it is a didactic system in which the individualization of teaching can be achieved. The primary use of educational tools for mathematical purposes is quality verification of results. There are various tools for developing student logic based on interactivity. Mathematically educational tools are designed for innovative, interactive and dynamic learning in a variety of areas of mathematics. This paper aims to describe the application of educational tools with which can develop interactivity and help pupils and students understand better, more clearly mathematics and to understand that it is all around us, that it is our everyday life.
\end{abstract}

Keywords: Individualization, Computer, Educational Software

\section{Introduction}

One of the most significant problems that accompany traditional mathematics teaching, as well as teaching in general, is in its organization, in which mathematics curricula, teaching methods and teaching conditions are the same for all students. [1] Namely, the curriculum, teaching methods, teacher's approach to students, are adapted to the imagined "average" student. In such classes, "better" students stagnate, because they are not required to make a greater intellectual effort, and "weaker" are not able to follow the average level of other students. "During the second half of the last century, the problems of individualization of teaching were dealt with by many pedagogues, psychologists, didactics, including Ganje, Budarnij, Kruteckij and many others". Adapting the teaching of mathematics to the possibilities of each individual student - individualization of teaching, becomes one of the basic issues of modern teaching of mathematics. It is widely accepted among modern didactics that the individualization of teaching is a "permanent innovation" (Mandic, 1995), as well as that "the most significant innovative force that affects the development and modernization of teaching is contained in the choice of ways and procedures of individualization." 2003, 68), which means that the principle of individualization of teaching is one of the most important requirements of modern teaching. In accordance with the above, there is also the position that "Individualization of teaching in didactics is explained as a didactic principle, as a precondition for the rationalization of teaching and as a permanent innovation. [3]

Emphasizing that individualization of teaching is an 
imperative of the time in which we live, one of the famous authors in this field specifies that individualization is such planning, organization and implementation of the curriculum, daily lessons and the entire educational activity, which respects the interests, needs and opportunities of each student. maximally develops his strengths and abilities and provides preconditions for creative involvement in the teaching process "(Mandic, 1995) (Đukic, 2003, 68). On the other hand, the introduction of computers and educational software in the teaching process creates conditions for knowledge, skills and habits to be acquired in a more acceptable way, and at the same time the student is able to "learn by himself", to "know how". In other words, the student takes on a new role - the student is an active subject in the teaching process. [2]

\section{Application of Computers in the Modern Teaching Process}

The most important task of the modern educational process is reflected in finding more efficient methods and forms of work. The rapid technological progress of human civilization is causing evolutionary needs for changes in the educational concept. New standards in the field of education have been adopted, which have significantly shifted old-fashioned notions and concepts of teaching. [4] The notion of knowledge is changing. Modern education requires the transformation of the traditional model reproduction of knowledge into a model of active knowledge building, where teachers and students are partners in joint action on building a knowledge base to be adopted. An active individual is forced to individually transform the collected information into knowledge. The role of the teacher in the school thus becomes somewhat different. He is no longer the center of the classroom where frontal teaching takes place, but an associate, who helps students to successfully process information into knowledge.

"In the last ten years, didactic media, teaching methods and forms of work in the function of raising the efficiency and effectiveness of the teaching process have been intensively developed and improved. The current organization of teaching is not modeled as a complete cognitive system. As a rule, there is no feedback. After the end of the class, the students do not know how successfully they have mastered the teaching contents, nor does the teacher have a more complete picture of the knowledge of all the students. Feedback should follow every step of the teaching process, which is not the case in the current practice. Teaching is based on an entropy rather than a systems approach. One of the reasons for this situation is the unfavorable didactic-technical environment in which teaching takes place." [5].

It is necessary to modernize the process of education in order to achieve a mutual connection between what children see, hear, understand and remember, that is, in order for them to adopt a certain matter as easily as possible. Also, teaching needs to be updated. The notion of actualization of teaching implies the systematic introduction of the elements of modern society and the needs of modern man into the teaching contents, and the application of modern teaching aids. In order for teaching to be actualized, it is necessary to introduce innovations in education. Innovation is a novelty in the practice of education, a change in the content or methods of work, in order to improve the quality of teaching.

Today's pedagogy strives to replace the established way of learning with a better and more efficient one, which would ensure that a larger number of children are more successfully prepared for active participation in the further development of science, technique and technology in a shorter time.

The Pyramid of Experiences warns children and adults to remember:

Only $10 \%$ of what they read - reading,

$20 \%$ of what they hear - listening to words,

$30 \%$ of what they see

$50 \%$ of what they see and hear - seeing pictures, actions or demonstrations,

$70 \%$ of what they say and write, what they play - creating drama, role playing,

$90 \%$ of what they do - doing something real, achieving current goals, searching for solutions [6].

\subsection{Computer-Assisted Teaching}

If we look today, there is a trend of changes in the educational system in the world. The traditional form of teaching, where teaching is a central part of the teaching process that has a teacher for its center, is such that the student is in the center. For that reason, educational institutions have to go through great changes. [6] Research in the world shows that computers are effective teaching aids that enable control, regulation, management of teaching and learning through constant feedback, which has strong motivational power and which is the basis of a system of evaluation and fair assessment of student work. Computer devices enable a completely different organization of teaching and educational work, appropriate to the abilities and interests of each student, and then provide better and more efficient emission, transmission and absorption of knowledge.

Computer-assisted teaching and learning leads to progress in knowledge acquisition. The computer gives students not only lessons and questions, but also instructions for solving the set tasks. Teaching with the help of computers leaves the teacher more time for more creative work, ie for educational activities, for pedagogical and professional training, for program innovation, etc. It has been noticed that teaching with the help of computers enables the development of memory, independence in learning, raises the educational level, builds sensitivity to the problem, openness, flexibility, tolerance, independence in work. This puts knowledge more successfully in the function of human development [7]. 


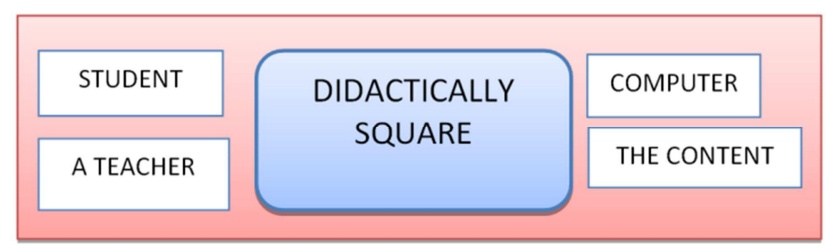

Figure 1. Didactic quadrilateral.

\subsection{Models of Computer use in Teaching}

The computer has several functions in teaching. It is used when practicing motor skills with the use of a mouse and keyboard. It is also used as a teaching tool. It can replace the largest number of teaching aids (TV, overhead projector...). The use of computers can avoid the disadvantages of traditional teaching: [8]

1. The student is not a passive object of teaching, but learns actively, independently according to his pace. He is the subject of teaching.

2. The student knows exactly what is correct in his answer and what is wrong. He continuously received feedback on the accuracy of his answers.

3. Computer programs used in teaching are divided into:

4. Exercise programs that form habits, abilities in students. They constantly inform students about the result.

5. Programs that communicate new knowledge-learning programs

6. Programs for solving various problems - the student works independently and tries to solve problems.

7. Computers in teaching:

8. They provide an opportunity for the teacher to raise the quality of teaching and to provide two-way communication in teaching.

9. Multimedia presentation contributes to easier maintenance of discipline in teaching and creating pedagogical situations in which students' responsibility for the success of teaching and learning will be expressed. Students more diligently follow the multimedia presentation, better remember the teaching content and more actively participate in the process of mastering new content

10. Faster acquisition of knowledge provides opportunities for students to think, analyze and conclude, to devote more time to learning, research, discovery and problem solving.

11. Modern computers can be used by students at home and thus acquire a variety of knowledge related to the curriculum.

12. All this suggests that the school must turn more to computer technology and prepare teachers for its use and create a situation in which the computer in the school will have the function it has in other activities [9].

\subsection{Features Provided by the Computer}

The possibilities provided by the computer are great. In the teaching process, with the help of computers, the work of both teachers and students can be significantly facilitated. It can be used for word processing, for compiling various tables and calculations, for making presentations, etc.

\subsubsection{Word Processing Programs}

These programs allow the user to manipulate the text. Among the numerous application programs, there are a very large number of programs used for word processing of socalled word processors or word processors. Each of the programs offers its own options and its own possibilities for word processing, each of them has its own solutions for individual elements of word processing.

From the appearance of the first, line word processors, where processing was performed line by line, without the possibility of returning for corrections of the previous line, to today's state-of-the-art word processing programs, various programs have changed.

Modern programs offer the possibility of editing (displaying) text, formatting, printing, applying dictionaries, checking grammatical correctness, adding graphics, drawings, etc. With the help of a word processing program, it is possible to create lesson preparations, notes, sketches, various invitations, school newspapers.

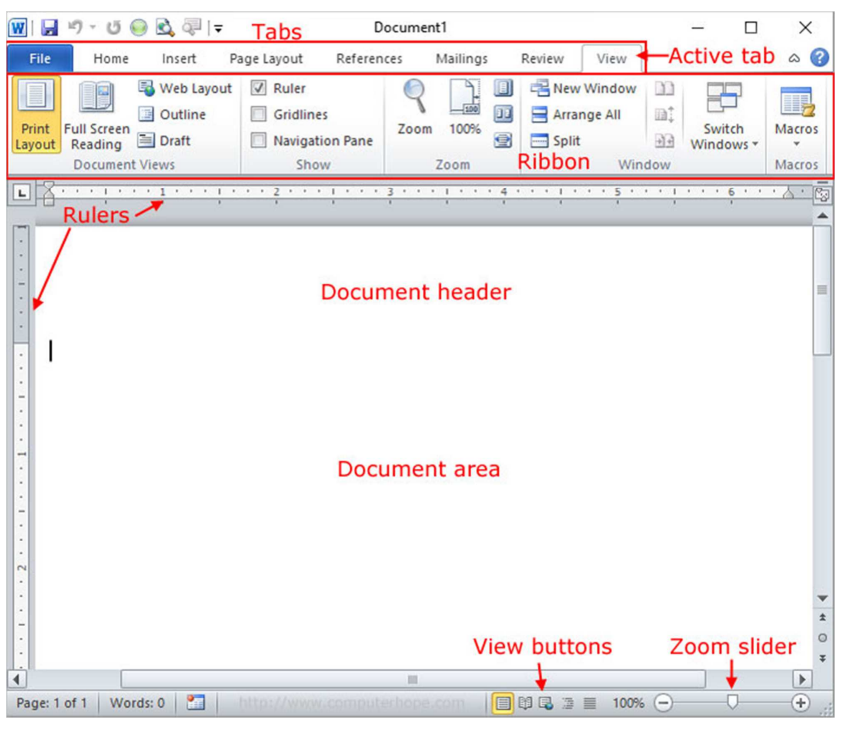

Figure 2. Line with icons for document formatting.

The advantages of documents created with the help of such programs are:

1. Saved documents can be used later.

2. Easy modification.

3. Sharing and sending over the Internet.

4. Playback and printing.

5. The teacher saves his time and energy.

6 . The quality of teaching increases.

Today's word processing programs have the ability to display textual material on the screen exactly as that material will look when printed.

The most famous word processing program is Microsoft Word, which is part of the Microsoft Office software package.

In a word processor, you are presented with a blank white 
sheet as shown below. The text is added to the document area and after it has been inserted formatted or adjusted to your preference. Below is an example of a blank Microsoft Word window with areas of the window highlighted.

\subsubsection{Programs for Working with Tables}

Programs for working with tables are used to display various contents in tabular form. And it is possible to apply various forms and functions starting from addition to complex logical and mathematical functions. Presentation and visualization of certain values is done with the help of graphs. The user types numeric or textual data into a single table location, called a cell, and then processes it.

Worksheets are usually integrated with other software, so they form a software set. These programs are primarily used to support decision-making, as well as in the processing of financial information, such as the income statement. Such programs can be used by students to calculate the circumference and area of various geometric bodies. They can also be successfully applied by teachers for creating class schedules, for calculating grades for written assignments, average of subjects and grades, etc.

An example of such a program is Microsoft Excel, which is part of the Microsoft Office software package.

\begin{tabular}{|c|c|c|c|c|c|c|}
\hline \multicolumn{2}{|c|}{ E8 } & \multicolumn{5}{|c|}{$\Rightarrow \quad f_{x}$} \\
\hline & A & B & C & D & $E$ & $\mathrm{~F}$ \\
\hline \multicolumn{7}{|l|}{1} \\
\hline \multicolumn{7}{|l|}{2} \\
\hline \multicolumn{7}{|l|}{3} \\
\hline \multicolumn{7}{|l|}{4} \\
\hline \multicolumn{7}{|l|}{5} \\
\hline \multicolumn{7}{|l|}{6} \\
\hline \multicolumn{7}{|l|}{7} \\
\hline \multicolumn{7}{|l|}{8} \\
\hline \multicolumn{7}{|l|}{9} \\
\hline \multicolumn{7}{|l|}{10} \\
\hline 11 & & & & & & \\
\hline
\end{tabular}

Figure 3. Table layout.

\subsubsection{Graphics Programs}

Graphics programs allow users to create, store, and display or print a variety of drawings and graphics. An example of such a program is Corel Draw.

Graphic Presentation - This software allows users to create pseudo-three-dimensional images, highlighted certain aspects of a drawing, and make a freehand drawing. These packages typically contain drawing tools, presentation templates, different font styles, routines for checking the correctness of written text.

Graph Analysis - These applications additionally provide the ability to display previously analyzed data, such as statistics in graphical formats such as bar charts, line charts, bulk charts. Charts can also include elements of different textures, labels, and headers.

Graphics Engineering - Various engineering software programs are available in a shortened application development time and increased productivity of sketching people and engineers.

\subsubsection{Presentation Programs}

Programs that can be used to make various presentations are very popular in the teaching process, because communication with the help of multiple senses enables more efficient transmission of information.

Advantages of presentations:

1. Image, animation and video sketch are displayed instead of static texts.

2. Computer presentation can be sent and posted on the Internet.

3. Easy editing and modification.

4. With the help of interactive and hypertextual content it can be used for independent learning.

5. With the help of presentations, students can illustrate their lectures, for the adoption of computer concepts. Lectures supported by multimedia PonjerPoint presentations are far more efficient and interesting than the classic ones. The presentation is prepared before class and its presentation in class allows you to save time that would be spent writing on the board, and the use of multimedia elements replaces the use of teaching aids.

The most famous presentation program is Microsoft PowerPoint, which is part of the Microsoft Office software package. The feature of this program is a large number of ready-made templates and ClipArt content (images, photos, sound and animation).

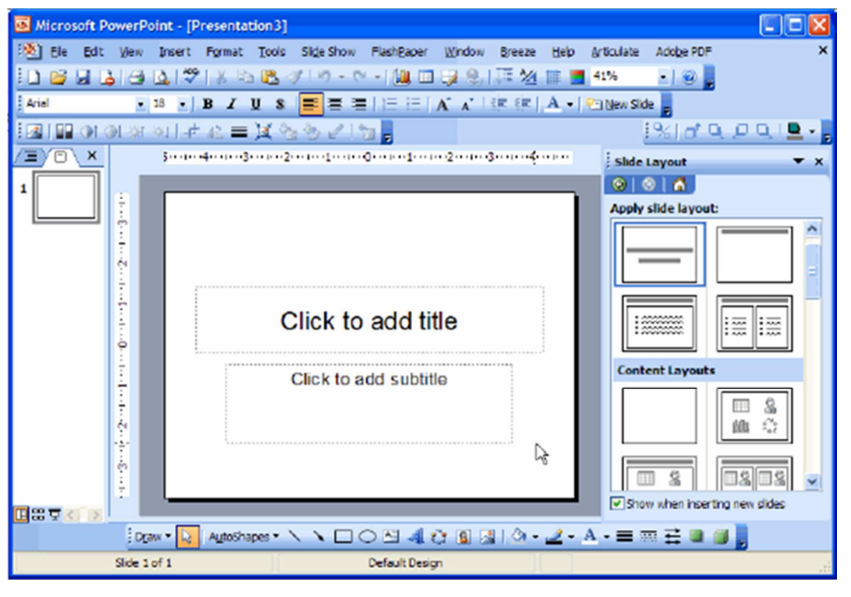

Figure 4. PowerPoint.

\section{Computer in Mathematics Teaching}

The computer-based teaching process is faster and more efficient than when the teaching process is performed only by the teacher. By using computers as teaching machines, from CBT and interactive video, interactive learning itself has developed. Also, according to [10], in that process, there is a greater activity of students because it has been proven that the material is easier to remember if it is presented visually. It is a well-known fact that educational technology has become an integral part of education, especially if we take into account the importance of teaching aids in mathematics teaching, as well as the need for them to be at hand in the 
teaching process on a daily basis. The intensive development of computers as well as their prevalence contributes to the improvement of the quality of teaching. Thus, nowadays, almost every student has access to a computer, so the learning environment is becoming richer, and educational work is becoming better. [11]

Effective results in the process of teaching mathematics are the basis for the application of computers in teaching, ie for the selection of educational software. The essence of the application of computers in the teaching of mathematics is the modernization of the teaching process. In that way, technical achievements are closer to the real world, because they indirectly help the learning process. "The computer is a technical tool that ensures that the goal and content of learning mathematics is achieved in an exemplary, organized and modern way. In that way, learning mathematical content using a computer is extremely useful. It is an integral process. Students develop a love not only for mathematics, but also for the entire science and for the creations of human civilization." [12]

The complexity of the application of computers in the teaching of mathematics comes from the organization of teaching, because material resources play a major role in this process. However, if we look at the results brought by modernized teaching, as well as the advantages over classical, traditional teaching, the necessity of introducing computers into the teaching process is clear. Also, in practice, it has been confirmed that teachers who are able to use computers in teaching mathematics, do not use other audio - visual teaching aids, because the computer successfully replaces them. By using computers in teaching mathematics, the student is provided with adequate help in solving problems, according to [13] in two basic ways:

1. direct help from computers, which is enabled by an intelligent system and simulations, which students can use at their own level of knowledge and

2. Indirect assistance provided by monitoring the work of students through a computer.

The mentioned types of help to the student can be provided by applying educational software programs. In addition to the stated advantages in relation to other teaching aids, the computer also enables practical manipulation in the study of geometric contents, which cannot be achieved with any teaching aids used in traditional teaching. As the teaching of mathematics is dynamic and requires students to actively adopt mathematical content, the computer contributes to this process in the following way. Namely, as students do not have the same abilities, so they adopt the material in different ways and in different time periods, the computer enables individualization of teaching, because each student can solve mathematical problem situations at his own pace. In this way, each student progresses according to his abilities. The use of computers in teaching, more precisely quality educational software, enables the adaptation of program material to the characteristics of the thought process and other characteristics of students that are individual. Of course, the computer should not be used on every occasion and at every hour. When the computer will be used depends on the teacher and how he planned the lesson. In addition, the computer does not push the teacher out of the teaching process, but only helps him to perform quality teaching work. Otherwise, the reactions of teachers to the introduction of computers in the teaching process are different and depend on their readiness to implement computers in the teaching process. It can be concluded that there are two basic requirements that need to be met in a modern school in relation to this issue technical modernization of the workspace and training of teachers for a new interactive role. [14]

\section{Educational Software in Mathematics Teaching}

Most of the listed functions (except for the function computer - subject of study) performed by the computer in the teaching process, are of a general nature and, to a greater or lesser extent, characterize the use of computers in the teaching of most subjects. The basic factor that represents the essence of the application of computers in the teaching of a subject is educational software. Educational software in computer-assisted mathematics teaching certainly has some specifics, which are not characteristic of educational software used in the teaching of other subjects. [7] These specifics are conditioned by the need for educational software to be appropriate to the goals and tasks of teaching mathematics, age of students, teaching content, type of class, as well as didactic principles and teaching methods. It is especially important that the educational software in mathematics teaching provides conditions for: independent work and individualization of teaching, visualization of teaching content, with special emphasis on the application of problembased and research teaching methods. The paper (Kirsev, 1993), as one of the basic principles that should satisfy the educational software, emphasizes precisely - the possibility of individualization of teaching.

\subsection{Dynamic Geometric Systems}

Dynamic Geometry Systems (DGS) are widely used in geometry teaching in the world today. It is common that in systems of dynamic geometry, objects can be observed analytically, through their coordinates and equations. Conversely, "it is not possible to set coordinates and equations and then a graphical presentation of given objects that could be changed directly with the mouse in these systems" (Herceg, D., Herceg, Đ. 2009, 2). The most used representatives of these systems are: Geometer's Sketchpad, Cabri Geometry, C. a. R. - Compass and Ruler, Cinderella Geometridge, Dr. Geo, EUCLID DynaGeo, Geonect.

\subsection{Computer Algebra Systems}

Programs that provide the possibility for analytical processing of geometry, as well as the processing of teaching contents of mathematical analysis, algebra, numerical mathematics, etc., are computer algebra systems (Computer 
Algebra Systems, CAS). With these programs, it is possible to visualize the coordinates and equations of geometric objects, ie. graphical interpretation is possible, as well as observation of changes in algebraic objects on their graphical representations. Also, graphical interpretations, so-called Plots, cannot be changed with the mouse. "Assigning algebraic objects is not always simple, since the syntax of these systems often has very little in common with the usual school notation", (Herceg, D., Herceg, Đ. 2009, 3). These programs can, among other things, solve algebraic systems, determine, for example, conic sections. CASs are very powerful general purpose tools, but they do not allow any direct dynamic changes in the field of analytical geometry. Well-known and frequently used representatives of this group of programs are: Derivatives and Maple.

\subsection{Combined DGS - CAS Software Systems}

Mathematica is a powerful software system designed for numerical, symbolic and graphical computing and visualization. In addition to practical application in the economy and industry, it is also used for scientific and educational purposes. This software package has been used for years in all phases of learning mathematics, from primary school to higher education institutions. Mathematica provides a complete environment for creating course materials, combining great computational capabilities as well as dynamic visualization capabilities, with professional documentation and presentation tools, giving this software package the best features of DGS and CAS programs. Mathematica is, structurally, divided into two parts: the core, which serves to interpret expressions and return results, and the user interface, which allows the creation and modification of documents containing program code, graphics, tables, sounds, etc. Communication with other applications is enabled using the MathLink protocol, which is used for communication between the kernel and the user interface, but also for connecting between the kernel and applications written in other programming languages. Mathematica can be installed on different versions of Linux, Mac OS X, and Windows, as well as on others operating systems.

GeoGebra is software that implements the best features of DGS and CAS program, and connects geometry and algebra. It was developed by Markus Hohenwarter from the University in Salzburg to teach mathematics. GeoGebra is free and available at more than 30 languages, including Serbian. [15]

On the one hand, GeoGebra is a DGS tool. They can be constructed directly interactively points, vectors, lines, and conic sections can be changed dynamically by displacement. Ellipses, hyperbolas and parabolas can be drawn next to circles. Tangent and polar constructions they also belong to the basic functions. On the other hand, equations are possible in GeoGebra and set the coordinates directly. GeoGebra knows both explicit and implicit equations straight and conical sections, parametric representation of straight as well as polar and Cartesian coordinates of points and vectors. [16] Since GeoGebra calculates numbers, angles, vectors, points, lines and conic sections, it can be said that GeoGebra is numerical CAS tool. This is why GeoGebra offers more geometric commands: determination centers longer, focus and vertices of conical sections. In addition, it gives the coefficient of direction, the vector direction and normal vector of a straight line, main axis and diameters of conical section, (Herceg, D., Herceg, Đ. 2009).

GeoGebra is written in Java, which allows it to be used independently of the operating system system, which is in use: Windows, Linux, MacOS X, or Unix. The program is very easy to use, and provides ideal conditions for independent work students from the above, very important, areas of school mathematics, geometry and algebra. Creating animations and simple illustrations of school content enable the teacher to acquaint students with basic mathematical concepts in a short time and very effectively and knowledge. [17]

Desktops created in GeoGebra can be transferred to html and word documents. In addition, constructions can be repeated at will, step by step, and automatically, and manually.

The dynamic unity of geometry and algebra in GeoGebra makes it easy for students experimental approach to mathematics. They can, as their own teachers, do it on their own progress, individually and discoverively to work and learn. With more frequent use of computers and this program and better training, especially for teachers, the organization of classes can be better and more interesting than before. Student reactions, feedback, will also be affected future organization of classes" (Herceg, D., Herceg, Đ. 2009, 4).

\section{Conclusion}

When planning and implementing classes, it is important that every mathematics teacher is guided by the following attitude: computer - is not a mechanical teacher, not a substitute, or an analogue of the teacher, but a teaching tool that strengthens and expands the possibilities of both students and teachers. teaching process.

In a quality atmosphere as a precondition for positive interactive relationships of actors in the teaching process, as well as applying the criteria of didactic modeling of teaching, creativity of teachers, combining different types of teaching and a new role of students in that process, will provide the desired quality in teaching. Individual teaching accompanied by the concept of programmed teaching with the support of a multimedia textbook is a new concept that primarily animates the student, and greatly facilitates the process of learning and studying in general. Multimedia in combination with methodology, didactics, pedagogy, certainly provides new opportunities in the implementation of teaching and enables the monitoring of new trends in education.

\section{References}

[1] Đorđević, J. (1981), Savremena nastava - organizacija ioblici, Naucna knjiga, Beograd. Obrad Aničic, TIO Conference, Cacak 2010. 
[2] Đukić, M. (2003), Didactic innovations as a challenge and choice, Association of Pedagogical Societies of Vojvodina, Novi Sad.

[3] Mandić, P. (1995), Individual complexity and education, Naucna knjiga, Belgrade. Jokic M. (2010). A look at the place of information technology in mathematics teaching. Pedagogical Reality, 56 (9-10), 869-881.

[4] Milošević, M. (3-4 / 2007): Application of new information technologies in the process of education, Pedagogical reality, "Vojvodjanska banka", Novi Sad, p. 249.

[5] Svetlana Andjelic, New information technologies in children's education, 2007.

[6] A. Savić, Methods of development and application of XML web service as a support to the traditional educational process, doctoral dissertation, Technical Faculty "Mihajlo Pupin", 2007.

[7] Tall, D. (1993), Computer environments for the learning of mathematics, Didactics of Mathematics as a Scientific Discipline - The State of the Art, ed R. Biehler, R. Scholtz, R. W. Sträßer, B. Winkelmann. Dordrecht: Kluwer, 189-199.

[8] Cekuš G. - Namestovski, Ț. (2005): Application of computers in classes. International scientific-professional conference: Contemporary information and educational technologies and new media in education, Sombor.

[9] D. Mandic, Didactic-information innovations in education, Belgrade 2003.
[10] Savicic J. (2011). Interactive multimedia learning and teaching using computer networks. Norma, 16 (1), 57-66.

[11] Mićanović V., Modernization of initial mathematics teaching using computers, Pedagoška stvarnost, 2007, vol. 53, no. 7-8, p. $733-748$.

[12] Mićanović, V. (2008): The Place and Role of Computers in Initial Teaching Mathematics, Innovations in teaching, vol. 21, No. 3, p. 104-113.

[13] Jokic M. (2010). A look at the place of information technology in mathematics teaching. Pedagogical Reality, 56 (9-10), 869881

[14] Mićanović V. (2012). Educational technology in the initial teaching of mathematics. Pedagogical Reality, 58 (3), p. 547558 .

[15] [Hohenwarter, 2008] Hohenwarter, M. (2008). GeoGebra. http://www.geogebra.org.

[16] GeoGebra (2015a). Chemistry. Available at https://www.geogebra.org/m/C4M42dr7 (accessed 12 March 2015).

[17] Herceg, D., Herceg, Đ. (2009), GeoGebra - in mathematics teaching, Republic seminars on teaching mathematics and computer science in primary and secondary schools, Belgrade, January 17 and 18, 2009. 